\title{
LUTEIN AND ZEAXANTHIN CONTENT IN MILLING FRACTIONS OF SELECTED WHEAT SPECIES AND VARIETIES
}

\section{Lacko-Bartošová Magdaléna*, Leváková L’udmila}

Department of Sustainable Agriculture and Herbology, Faculty of Agrobiology and Food Resources,

Slovak University of Agriculture in Nitra, Slovakia

\section{OBSAH LUTEÍNU A ZEAXANTÍNU V MLYNSKÝCH FRAKCIÁCH VYBRANÝCH DRUHOV A ODRÔD PŠENÍC}

\author{
Lacko-Bartošová Magdaléna, Leváková L’udmila \\ Received 25. 6. 2017 \\ Revised 29. 6. 2017 \\ Published 27. 11. 2017
}

\begin{abstract}
Lutein and its isomer, zeaxanthin, belong to a class of carotenoids called xanthophylls. They are the main carotenoids in cereal grains. A number of human epidemiological and clinical studies have shown that their intake is associated with reduced incidence of age-related macular degeneration, the leading cause of irreversible blindness in elderly people, and cataracts. In addition, lutein may have protective benefits against skin cancer and may also help to prevent cardiovascular diseases. The objective of the present study was to evaluate lutein and zeaxanthin content in selected varieties of wheat species produced in organic farming system and their distribution in milling fractions. A field stationary experiment was established at the Research Experimental Station Dolná Malanta in western Slovakia, during the years 2013-2015. The significantly highest average lutein content was detected in bran fraction $(2.546 \mu \mathrm{g} / \mathrm{g}$ dry weight) and the lowest in flour $(1.675 \mu \mathrm{g} / \mathrm{g}$ dry weight). Among wheat species, the significantly highest content of lutein was achieved in the bran of Triticum monococcum L. (5.080 $\mathrm{\mu g} / \mathrm{g}$ dry weight). The highest average concentrations of lutein were observed in the variety Franckenkorn of Triticum spelta L. $(2.706 \mu \mathrm{g} / \mathrm{g}$ dry weight), particularly in bran fraction. In the case of zeaxanthin, the significantly highest content was determined in whole grain of Triticum monococcum $(0.193 \mu \mathrm{g} / \mathrm{g}$ dry weight). No significant differences in the zeaxanthin content between milling fractions were determined. Triticum monococcum was the most important source of carotenoids, followed by Triticum spelta and Triticum dicoccon.
\end{abstract}

Keywords: lutein; milling fractions; organic farming system; wheat; zeaxanthin

\section{Úvod}

Karotenoidy sú prírodné lipofilné pigmenty so schopnostou chránit’ rastliny pred poškodením vol'nými radikálmi indukovanými svetlom. Zodpovedajú za žlté, oranžové a červené sfarbenie ovocia, zeleniny a zín cereálií (Žilič et al., 2011). Cereálie sú vo všeobecnosti významným zdrojom karotenoidov, ktoré sú koncentrované predovšetkým v endosperme zŕn. Hlavný priaznivý účinok

*Corresponding author: Magdaléna Lacko-Bartošová, Department of Sustainable Agriculture and Herbology, Faculty of Agrobiology and Food Resources, Slovak University of Agriculture in Nitra, Slovakia, $\square$ magdalena.lacko-bartosova@uniag.sk 
karotenoidov spočíva $\mathrm{v}$ ich antioxidačných schopnostiach, pre ktoré sa uplatňujú v prevencii degeneratívnych procesov a ako antikarcinogénne látky (Šivel et al., 2013).

Najviac prevládajúcimi karotenoidmi v zrne cereálií sú luteín a zeaxantín, ktoré patria medzi prirodzene sa vyskytujúce xantofyly. Luteín je v zrnách pšenice prítomný v obalových vrstvách, endosperme a zárodku, čo predstavuje približne 80 - 90 \% celkového obsahu karotenoidov. Podiel'a sa na svetlo krémovej až žltej farbe pšeničných finálnych výrobkov (Leenhardt et al., 2006a).

Luteín sa významne uplatňuje v biochémii zrakového vnemu. Hromadí sa v tzv. žltej škvrne (z lat. macula lutea) na sietnici a $v$ očnej šošovke. Chráni oči pred poškodením ultrafialovým žiarením a následnou stratou zraku. Spolu so zeaxantínom má klúčovú úlohu v prevencii vekom podmienenej makulárnej degenerácie, ktorá vedie k strate zraku v strede zorného pola v dôsledku poškodenia očnej sietnice. Takisto znižuje riziko sivého zákalu (katarakty), ktorý je hlavnou príčinou zhoršeného zraku v rozvinutých krajinách (Sajilata et al., 2008; Šivel et al., 2013).

Cielom príspevku bolo zhodnotit’ obsah luteínu a zeaxantínu vo vybraných odrodách pšenice špaldovej (Triticum spelta L.), pšenice dvojzrnovej (Triticum dicoccon Schrank) a pšenice jednozrnovej (Triticum monococcum L.) a ich distribúciu v múke, celozrnnej múke a otrubách.

\section{Materiál a metódy}

Maloparcelový pol'ný pokus bol založený v ekologickom systéme hospodárenia na experimentálnej báze Fakulty agrobiológie a potravinových zdrojov Slovenskej pol'nohospodárskej univerzity v Nitre Dolná Malanta. Geograficky sa územie nachádza v západnej časti Žitavskej pahorkatiny, ktorej charakteristický trojuholníkový tvar vymedzuje pohorie Tríbeč, rieky Nitra a Žitava. Lokalita má výmeru cca 19 ha a rovinatý charakter s miernym sklonom k juhu. Nadmorská výška v lokalite sa pohybuje v rozmedzí 177 - 180 m n. m. (Slovík a Libant, 1996). Územie patrí do teplého agroklimatického regiónu. Dlhodobá priemerná teplota vzduchu dosahuje hodnotu $9,8{ }^{\circ} \mathrm{C}$ a dlhodobý ročný úhrn zrážok za obdobie rokov 1961 - 1990 je 532,5 mm (Špánik et al., 1996). Hlavnou pôdnou jednotkou na experimentálnej báze je hnedozem pseudoglejová na sprašových a polygénnych hlinách. Pôda je bez skeletu, stredne t’ažká, hlinitá (Tobiášová a Šimanský, 2009).

Pokus bol založený blokovou metódou s náhodným usporiadaním v štyroch opakovaniach. Vel'kost' plochy jedného opakovania bola $10 \mathrm{~m}^{2}$. Biologický materiál predstavovali tri odrody pšenice špaldovej (Oberkulmer Rotkorn, Rubiota, Franckenkorn) a pšenice dvojzrnovej (Agnone, Molise sel Colli, Farvento) a jedna odroda pšenice jednozrnovej (Einkorn). Odrody pšenice boli pestované v podmienkach ekologického systému hospodárenia, bez použitia priemyselných hnojív a prípravkov na ochranu rastlín. V pokuse bol hodnotený vplyv pestovatel'ského ročníka a odrôd na obsah luteínu a zeaxantínu v múke, celozrnnej múke a otrubách.

Karotenoidy boli stanovené chromatograficky modifikovanou metódou podla metodiky HerreroBarbudo et al. (2005) a Ligor a Buszewski (2012). Do 50 ml túb sa navážil 1 g vzorky a k navážke sa pridal acetón. Tuby sa vložili na 15 minút do ultrazvukového kúpel’a a nechali sa centrifugovat’ pri $9000 \times$ g po dobu 5 minút. Z túb sa odobralo $15 \mathrm{ml}$ extrakčného roztoku, ktorý sa nechal dosucha odparit' vo vákuovej rotačnej odparke pri teplote $40{ }^{\circ} \mathrm{C}$. Zvyšky z odparky sa rozpustili v $2 \mathrm{ml}$ mobilnej fáze. Vzorka bola centrifugovaná pri $15000 \times$ g po dobu 10 minút a následne injekovaná do detekčného systému Agilent 1260 HPLC s kolónou Symmetry C-18 (Waters, $250 \times 4,6$ mm, vel'kost' častíc $5 \mu$ m, teplota kolóny $30^{\circ} \mathrm{C}$ ) a mobilnou fázou acetonitril/metylénchlorid/metanol (70:20:10 v/v/v). Prietok plynu bol $1 \mathrm{ml} / \mathrm{min}$. Na identifikáciu karotenoidov bol použitý simultánne hmotnostný spektrometer 
HPLC Agilent Triple Quadrupol 6410 MS/MS s elektrosprejovou ionizáciou (ESI mód) pri pozitívnej ionizácii (kapilárne napätie $5000 \mathrm{~V}$, teplota plynu $325^{\circ} \mathrm{C}$, prietok plynu $10 \mathrm{l} / \mathrm{min}$, vaporizer $200{ }^{\circ} \mathrm{C}$, nebulizer 40 psi). Pre luteín bol použitý SIM mód s iónovými signálmi $\mathrm{m} / \mathrm{z} 551$, pre zeaxantín $\mathrm{m} / \mathrm{z}$ 569. Získané údaje boli štatisticky vyhodnotené s využitím viacfaktorovej analýzy rozptylu (ANOVA) $\checkmark$ programe STATISTICA, verzia 10.0. Preukazné rozdiely boli hodnotené na hladine významnosti $\alpha=0,05 \%$ s použitím Fisherovho LSD testu.

\section{Výsledky a diskusia}

Počas rokov 2013 - 2015 bol analyzovaný obsah luteínu v mlynských frakciách (múke, celozrnnej múke a otrubách) vybraných druhov pšeníc a ich odrôd (Tabul'ka 1 a 2). Spomedzi jednotlivých frakcií bol preukazne najvyšší priemerný obsah luteínu za všetky hodnotené druhy v otrubách $(2,546$ ㅆg/g sušiny) a najnižší v múke (1,675 $\mu \mathrm{g} / \mathrm{g}$ sušiny). Distribúcia obsahu luteínu v múke, celozrnnej múke a otrubách odrôd Triticum dicoccon sa síce zvyšovala, avšak štatisticky nevýznamne. V prípade odrôd Triticum spelta bol obsah luteínu v múke a celozrnnej múke tiež štatisticky nevýznamný, v otrubách signifikantne vyšší.

Tabulka 1 Obsah luteínu v mlynských frakciách Triticum spelta L., Triticum dicoccon Schrank, Triticum monococcum L. ( $\mu \mathrm{g} / \mathrm{g}$ sušiny)

Table 1 Lutein content in milling fractions of Triticum spelta L., Triticum dicoccon Schrank, Triticum monococcum L. ( $\mu \mathrm{g} / \mathrm{g}$ dry matter)

\begin{tabular}{|l|c|c|c|c|}
\hline \multirow{2}{*}{ Druh pšenice } & \multicolumn{4}{|c|}{ Luteín, $\boldsymbol{\mu g} / \mathbf{g}$ sušiny } \\
\cline { 2 - 5 } & múka & celozrnná múka & otruby & priemer \\
\hline Triticum spelta & $1,571 \mathrm{a}$ & $1,804 \mathrm{a}$ & $2,488 \mathrm{~b}$ & $1,954 \mathrm{~b}$ \\
\hline Triticum dicoccon & $1,494 \mathrm{a}$ & $1,579 \mathrm{a}$ & $1,758 \mathrm{a}$ & $1,610 \mathrm{a}$ \\
\hline Triticum monococcum & $2,530 \mathrm{~b}$ & $3,492 \mathrm{c}$ & $5,080 \mathrm{~d}$ & $3,701 \mathrm{c}$ \\
\hline Priemer & $1,675 \mathrm{~A}$ & $1,949 \mathrm{~B}$ & $2,546 \mathrm{C}$ & \\
\hline Rok & \multicolumn{5}{|c|}{} \\
\hline $\mathbf{2 0 1 3}$ & $2,179 \mathrm{~d}$ & $2,599 \mathrm{e}$ & $2,934 \mathrm{f}$ & $2,571 \mathrm{~b}$ \\
\hline $\mathbf{2 0 1 4}$ & $0,988 \mathrm{a}$ & $1,103 \mathrm{a}$ & $1,429 \mathrm{~b}$ & $1,173 \mathrm{a}$ \\
\hline $\mathbf{2 0 1 5}$ & $1,856 \mathrm{c}$ & $2,144 \mathrm{~cd}$ & $3,274 \mathrm{~g}$ & $2,425 \mathrm{~b}$ \\
\hline
\end{tabular}

a, b,c, d, e, f, g - preukazný rozdiel na hladine významnosti $\alpha=0,05 \%$; ANOVA - LSD test; malé písmená preukaznost' v stipci; vel'ké písmená - preukaznost' v riadku

Obsah luteínu v Triticum monococcum bol zo všetkých hodnotených druhov najvyšší a významne ovplyvnený frakciami zomletého zrna. Preukazne najvyššie koncentrácie luteínu boli zistené v otrubách Triticum monococcum $(5,080 \mu \mathrm{g} / \mathrm{g}$ sušiny).

Podla výsledkov štúdie Leenhardt et al. (2006b) koncentrácia luteínu v Triticum monococcum, vo frakcii celozrnnej múky, dosiahla priemerne 5,75 $\pm 0,17 \mu \mathrm{g} / \mathrm{g}$ sušiny, čo boli najvyššie hodnoty v porovnaní s ostatnými testovanými druhmi pšeníc a porovnatel'né s našimi výsledkami. Takisto Abdel-Aal et al. (2007) zistili najvyššie priemerné hodnoty luteínu (až 7,41 $\mu \mathrm{g} / \mathrm{g}$ sušiny) v Triticum monococcum, pričom koncentrácie tohto karotenoidu boli ovplyvnené viacerými environmentálnymi faktormi. 
Tabulka 2 Obsah luteínu v mlynských frakciách vybraných odrôd rodu Triticum ( $\mu \mathrm{g} / \mathrm{g}$ sušiny)

Table 2 Lutein content in milling fractions of selected varieties of genus Triticum ( $\mu \mathrm{g} / \mathrm{g}$ dry matter)

\begin{tabular}{|l|c|c|c|c|}
\hline \multirow{2}{*}{ Druh pšenice } & \multicolumn{4}{c|}{ Luteín, $\mathbf{~ g / g}$ sušiny } \\
\cline { 2 - 5 } & múka & celozrnná múka & otruby & priemer \\
\hline Oberkulmer Rotkorn & $1,146 \mathrm{a}$ & $1,387 \mathrm{ab}$ & $1,808 \mathrm{bcde}$ & $1,447 \mathrm{a}$ \\
\hline Rubiota & $1,391 \mathrm{ab}$ & $1,671 \mathrm{bcd}$ & $2,069 \mathrm{defg}$ & $1,710 \mathrm{a}$ \\
\hline Franckenkorn & $2,175 \mathrm{efg}$ & $2,354 \mathrm{fg}$ & $3,588 \mathrm{~h}$ & $2,706 \mathrm{~b}$ \\
\hline \multicolumn{5}{|c|}{ Triticum dicoccon } \\
\hline Agnone & $1,408 \mathrm{ab}$ & $1,723 \mathrm{bcde}$ & $1,642 \mathrm{bcd}$ & $1,591 \mathrm{a}$ \\
\hline Molise sel Colli & $1,595 \mathrm{abc}$ & $1,370 \mathrm{ab}$ & $1,680 \mathrm{bcd}$ & $1,548 \mathrm{a}$ \\
\hline Farvento & $1,478 \mathrm{ab}$ & $1,644 \mathrm{bcd}$ & $1,953 \mathrm{cdef}$ & $1,692 \mathrm{a}$ \\
\hline \multicolumn{5}{|c|}{ Triticum monococcum } \\
\hline Einkorn & $2,530 \mathrm{~g}$ & $3,492 \mathrm{~h}$ & $5,080 \mathrm{i}$ & $3,701 \mathrm{c}$ \\
\hline
\end{tabular}

a, b,c, d, e, f, g, h, i - preukazný rozdiel na hladine významnosti $\alpha=0,05 \%$; ANOVA - LSD test

Na obsah luteínu mali signifikantný vplyv odrody, pestovatel'ské roky, avšak aj interakcia odroda $\times$ rok. Medzi odrodami Triticum dicoccon neboli zistené štatisticky významné rozdiely z hladiska obsahu luteínu. Spomedzi odrôd Triticum spelta boli preukazne najvyššie priemerné koncentrácie tohto karotenoidu v odrode Franckenkorn $(2,706 \mu \mathrm{g} / \mathrm{g}$ sušiny), pričom najzastúpenejší bol v otrubovej frakcii.Preukazne najvyšším priemerným obsahom luteínu bola charakteristická odroda Triticum monococcum - Einkorn (3,701 $\mathrm{gg} / \mathrm{g}$ sušiny). Preukazné rozdiely v obsahu luteínu boli zistené aj medzi druhmi v jednotlivých rokoch (Tabul'ka 3), pričom najnižší obsah bol v roku 2014 pri Triticum dicoccon

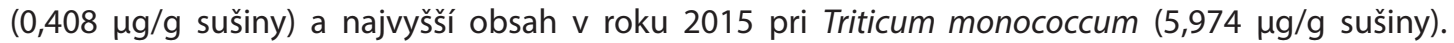
Preukazné rozdiely neboli zistené pri Triticum spelta medzi rokmi 2014 a 2015 a pri Triticum dicoccon medzi rokmi 2013 a 2015.

Tabulka 3 Štatistické zhodnotenie obsahu luteínu v jednotlivých druhoch pšeníc za obdobie rokov $2013-2015$ ( $\mu \mathrm{g} / \mathrm{g}$ sušiny)

Table 3 Statistical analysis of lutein content in selected wheat species during the years 2013-2015 ( $\mu \mathrm{g} / \mathrm{g}$ dry matter)

\begin{tabular}{|l|c|c|c|}
\hline Rok & Triticum spelta & Triticum dicoccon & Triticum monococcum \\
\hline $\mathbf{2 0 1 3}$ & $3,136 \mathrm{~d}$ & $2,196 \mathrm{c}$ & $2,002 \mathrm{c}$ \\
\hline $\mathbf{2 0 1 4}$ & $1,288 \mathrm{~b}$ & $0,408 \mathrm{a}$ & $3,126 \mathrm{~d}$ \\
\hline $\mathbf{2 0 1 5}$ & $1,439 \mathrm{~b}$ & $2,228 \mathrm{c}$ & $5,974 \mathrm{e}$ \\
\hline
\end{tabular}

a, b,c, d, e - preukazný rozdiel na hladine významnosti $\alpha=0,05 \%$; ANOVA - LSD test

Z hladiska priemerného obsahu zeaxantínu neboli medzi jednotlivými mlynskými frakciami štatisticky preukazné rozdiely (Tabul'ka 4). Spomedzi všetkých hodnotených druhov bol obsah zeaxantínu v Triticum monococcum preukazne najvyšší, pričom najvyššie koncentrácie tohto karotenoidu boli

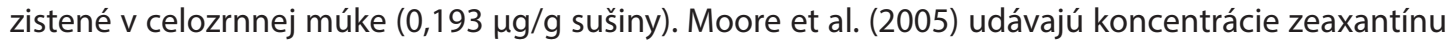


v zrne celozrnných cereálií v rozmedzí 0,2 - 0,39 $\mu \mathrm{g} / \mathrm{g}$. Na obsah zeaxantínu mal signifikantný vplyv ročník, ako aj interakcia ročník × frakcie múky. V roku 2015 bol zistený preukazne najvyšší priemerný obsah zeaxantínu $(0,183 \mu \mathrm{g} / \mathrm{g}$ sušiny).

Tabulka 4 Obsah zeaxantínu v mlynských frakciách Triticum spelta L., Triticum dicoccon Schrank, Triticum monococcum $\mathrm{L}$. ( $\mu \mathrm{g} / \mathrm{g}$ sušiny)

Table 4 Zeaxanthin content in milling fractions of Triticum spelta L., Triticum dicoccon Schrank, Triticum monococcum $\mathrm{L}$. ( $\mu \mathrm{g} / \mathrm{g}$ dry matter)

\begin{tabular}{|l|c|c|c|c|}
\hline \multirow{2}{*}{ Druh pšenice } & \multicolumn{4}{|c|}{ Zeaxantín, $\boldsymbol{\mu g} / \mathbf{g}$ sušiny } \\
\cline { 2 - 5 } & múka & celozrnná múka & otruby & priemer \\
\hline Triticum spelta & $0,074 \mathrm{a}$ & $0,084 \mathrm{a}$ & $0,092 \mathrm{a}$ & $0,083 \mathrm{a}$ \\
\hline Triticum dicoccon & $0,088 \mathrm{a}$ & $0,091 \mathrm{a}$ & $0,084 \mathrm{a}$ & $0,088 \mathrm{a}$ \\
\hline Triticum monococcum & $0,170 \mathrm{c}$ & $0,193 \mathrm{c}$ & $0,124 \mathrm{~b}$ & $0,163 \mathrm{~b}$ \\
\hline Priemer & $0,093 \mathrm{~A}$ & $0,103 \mathrm{~A}$ & $0,093 \mathrm{~A}$ & - \\
\hline Rok & \multicolumn{5}{|c|}{} \\
\hline $\mathbf{2 0 1 3}$ & $0,051 \mathrm{a}$ & $0,054 \mathrm{a}$ & $0,058 \mathrm{a}$ & $0,054 \mathrm{a}$ \\
\hline $\mathbf{2 0 1 4}$ & $0,056 \mathrm{a}$ & $0,050 \mathrm{a}$ & $0,050 \mathrm{a}$ & $0,052 \mathrm{a}$ \\
\hline $\mathbf{2 0 1 5}$ & $0,174 \mathrm{~b}$ & $0,203 \mathrm{c}$ & $0,172 \mathrm{~b}$ & $0,183 \mathrm{~b}$ \\
\hline
\end{tabular}

a, b,c, d, e, f, g - preukazný rozdiel na hladine významnosti $\alpha=0,05 \%$; ANOVA - LSD test; malé písmená preukaznost' v stípci; vel'ké písmená - preukaznost' v riadku

Tabulka 5 Obsah zeaxantínu v mlynských frakciách vybraných odrôd rodu Triticum ( $\mu \mathrm{g} / \mathrm{g}$ sušiny)

Table 5 Zeaxanthin content in milling fractions of selected varieties of genus Triticum $(\mu \mathrm{g} / \mathrm{g}$ dry matter)

\begin{tabular}{|l|c|c|c|c|}
\hline \multirow{2}{*}{ Druh pšenice } & \multicolumn{4}{c|}{ Zeaxantín, $\mathbf{\mu g} / \mathbf{g}$ sušiny } \\
\cline { 2 - 5 } & múka & celozrnná múka & otruby & priemer \\
\hline Oberkulmer Rotkorn & $0,068 \mathrm{a}$ & $0,068 \mathrm{a}$ & $0,078 \mathrm{ab}$ & $0,071 \mathrm{a}$ \\
\hline Rubiota & $0,084 \mathrm{abc}$ & $0,083 \mathrm{ab}$ & $0,079 \mathrm{ab}$ & $0,082 \mathrm{abc}$ \\
\hline Franckenkorn & $0,069 \mathrm{a}$ & $0,101 \mathrm{bcd}$ & $0,120 \mathrm{~d}$ & $0,097 \mathrm{~cd}$ \\
\hline \multicolumn{5}{|c|}{ Triticum dicoccon } \\
\hline Agnone & $0,090 \mathrm{abc}$ & $0,075 \mathrm{ab}$ & $0,067 \mathrm{a}$ & $0,077 \mathrm{ab}$ \\
\hline Molise sel Colli & $0,087 \mathrm{abc}$ & $0,098 \mathrm{bcd}$ & $0,110 \mathrm{~cd}$ & $0,098 \mathrm{~d}$ \\
\hline Farvento & $0,087 \mathrm{abc}$ & $0,098 \mathrm{bcd}$ & $0,076 \mathrm{ab}$ & $0,087 \mathrm{bcd}$ \\
\hline \multicolumn{5}{|c|}{ Triticum monococcum } \\
\hline Einkorn & $0,170 \mathrm{e}$ & $0,193 \mathrm{e}$ & $0,124 \mathrm{~d}$ & $0,163 \mathrm{e}$ \\
\hline
\end{tabular}

a, b, c, d, e - preukazný rozdiel na hladine významnosti $\alpha=0,05 \%$; ANOVA - LSD test 
Signifikantný vplyv na obsah zeaxantínu mali tiež odrody, pestovatel'ské roky, avšak aj interakcia odroda $\times$ rok (Tabulka 5 a 6). Spomedzi odrôd Triticum spelta bola preukazne najvyššími koncentráciami zeaxantínu charakteristická odroda Franckenkorn, pričom najvýznamnejšie bol zastúpený v otrubách $(0,120 \mu \mathrm{g} / \mathrm{g}$ sušiny). Pri odrodách Triticum dicoccon Molise sel Colli a Farvento bol obsah zeaxantínu v múke a celozrnnej múke štatisticky nevýznamný. Preukazne najvyšší obsah bol zistený v odrode Molise sel Colli, a to taktiež v otrubovej frakcii ( $0,110 \mu \mathrm{g} / \mathrm{g}$ sušiny). Pri odrode Einkorn bol zaznamenaný preukazne vyšší obsah zeaxantínu v múke a celozrnnej múke ako v otrubách. Táto odroda sa vyznačovala preukazne najvyšším priemerným obsahom zeaxantínu $(0,163 \mu \mathrm{g} / \mathrm{g}$ sušiny) spomedzi všetkých odrôd pšeníc. Z hladiska rokov bol preukazne najnižší obsah zeaxantínu v roku 2014 pri Triticum dicoccon (0,013 $\mu \mathrm{g} / \mathrm{g}$ sušiny) a najvyšší obsah v roku 2015 pri Triticum monococcum $(0,430 \mu \mathrm{g} / \mathrm{g}$ sušiny). Preukazné rozdiely neboli zistené pri Triticum spelta medzi rokmi 2013 a 2015 a pri Triticum monococcum medzi rokmi 2013 a 2014.

Tabulka 6 Štatistické zhodnotenie obsahu zeaxantínu v jednotlivých druhoch pšeníc za obdobie rokov 2013 - 2015 ( $\mu \mathrm{g} / \mathrm{g}$ sušiny)

Table 6 Statistical analysis of zeaxanthin content in selected wheat species during the years 2013-2015 ( $\mu \mathrm{g} / \mathrm{g}$ dry matter)

\begin{tabular}{|l|c|c|c|}
\hline Rok & Triticum spelta & Triticum dicoccon & Triticum monococcum \\
\hline $\mathbf{2 0 1 3}$ & $0,068 \mathrm{c}$ & $0,046 \mathrm{~b}$ & $0,038 \mathrm{ab}$ \\
\hline $\mathbf{2 0 1 4}$ & $0,102 \mathrm{~d}$ & $0,013 \mathrm{a}$ & $0,020 \mathrm{ab}$ \\
\hline $\mathbf{2 0 1 5}$ & $0,080 \mathrm{c}$ & $0,203 \mathrm{e}$ & $0,430 \mathrm{f}$ \\
\hline
\end{tabular}

a, b, c, d, e - preukazný rozdiel na hladine významnosti $\alpha=0,05 \%$; ANOVA - LSD test

\section{Závery}

V príspevku bol zhodnotený vplyv pestovatel'ského ročníka a odrody na obsah luteínu a zexantínu v Triticum spelta, Triticum dicoccon a Triticum monococcum, ako aj distribúcia týchto karotenoidov v jednotlivých mlynských frakciách. Pestovatel'ský ročník mal štatisticky preukazný vplyv na obsah luteínu a zeaxantínu. Spomedzi odrôd Triticum spelta boli preukazne najvyššie priemerné koncentrácie luteínu v odrode Franckenkorn, najmä v otrubovej frakcii. Preukazne najvyšším priemerným obsahom luteínu spomedzi všetkých odrôd bola charakteristická odroda Triticum monococcum - Einkorn. Signifikantne najvyšší priemerný obsah luteínu bol v otrubách, najnižší v múke. V prípade zeaxantínu bol jeho obsah preukazne najvyšší v Triticum monococcum, a to v celozrnnej múke. Z hladiska priemerného obsahu zeaxantínu neboli medzi jednotlivými mlynskými frakciami štatisticky preukazné rozdiely. Najdôležitejším zdrojom karotenoidov bola Triticum monococcum, nasledovaná Triticum spelta a Triticum dicoccon.

\section{Literatúra}

Abdel-Aal, E.S.M., Young, J.C., Rabalski, I. et al. 2007. Identification and quantification of seed carotenoids in selected wheat species. Journal of Agricultural and Food Chemistry, vol. 55, no. 3, p. 787-794.

Herrero-Barbudo, M.C., Granado-Lorencio, F., Blanco-Navarro, I. et al. 2005. Retinol and $\gamma$-tocopherol and carotenoids in natural and vitamin A- and E-fortified products commercialized in Spain. International Dairy Journal, vol. 15, no. 5, p. 521-526. 
Leenhardt, F., Lyan, B., Rock, E. et al. 2006a. Wheat Lipoxygenase Activity Induces Greater Loss of Carotenoids than Vitamin E during Breadmaking. Journal of Agricultural and Food Chemistry, vol. 54, no. 5, p. 1710-1715.

Leenhardt, F., Lyan, B., Rock, E., Rémésy, C. 2006b. Genetic variability of carotenoid concentration, and lipoxygenase and peroxidase activities among cultivated wheat species and bread wheat varieties. European Journal of Agronomy, vol. 25, no. 2, p. 170-176.

Ligor, M., Buszewski, B. 2012. Effect of Kale Cultivation Conditions on Biosynthesis of Xanthophylls. Journal of Food Research, vol. 1, no. 4, p. 74-84.

Moore, J., Hao, Z., Zhou, K., Luther, M., Costa, J., Yu, L. 2005. Carotenoid, tocopherol, phenolic acid and antioxidant properties of Maryland-grown soft wheat. Journal of Agricultural and Food Chemistry, vol. 53, p. 6649-6657.

Sajilata, M.G., Singhal, R.S., Kamat, M.Y. 2008. The carotenoid pigment zeaxanthin - a review. Comprehensive Reviews in Food Science and Food Safety, vol. 7, p. 29-50.

Slovík, R., Libant, V. 1996. Pôdno-geologické pomery okolia výskumnej bázy VŠP - Dolná Malanta. Agronomická fakulta a vývoj polnohospodárstva na Slovensku: zborník referátov z vedeckej konferencie, Nitra: VŠP, s. 122-124. ISBN 80-7137-276-5.

Šivel, M., Klejdus, B., Kráčma, S., Kubáň, V. 2013. Lutein - významný karotenoid ve výživě člověka. Chemické listy, roč. 107, s. 456-463.

Špánik, F., Repa, Š., Šiška, B. 1996. Klimatické a fenologické pomery Nitry (1961 - 1990). Bratislava: Slovenská bioklimatologická spoločnost' SAV, $60 \mathrm{~s}$.

Tobiášová, E., Šimanský, V. 2009. Kvantifikácia pôdnych vlastností a ich vzájomných vztảahov ovplyvnených antropickou činnostou. Nitra : SPU, 114 s. ISBN 978-80-552-0196-2.

Žilič, S., Šukalovič, V. H.-T., Dodig, D. et al. 2011. Antioxidant activity of small grain cereals caused by phenolics and lipid solubleantioxidants. Journal of Cereal Science, vol. 54, p. 417-424. 